\title{
Characteristics of small areas with high rates of hospital-treated self-harm: deprived, fragmented and urban or just close to hospital? A national registry study
}

\author{
I B O'Farrell, ${ }^{1}$ P Corcoran, ${ }^{2}$ I J Perry ${ }^{1}$
}

${ }^{1}$ Department of Epidemiology \& Public Health, University College Cork, Cork, Republic of Ireland

${ }^{2}$ National Suicide Research Foundation, University College Cork, Republic of Ireland

Correspondence to I B O'Farrell, Department of Epidemiology \& Public Health, University College Cork, Republic of Ireland; i.ofarrell@ucc.ie

Received 26 June 2014 Revised 11 September 2014 Accepted 24 September 2014

To cite: O'Farrell IB, Corcoran P, Perry IJ. J Epidemiol Community Health Published Online First: [please include Day Month Year] doi:10.1136/jech2014-204587

\section{ABSTRACT}

Background Previous research has shown an inconsistent relationship between the spatial distribution of hospital treated self-harm and area-level factors such as deprivation and social fragmentation. However, many of these studies have been confined to urban centres, with few focusing on rural settings and even fewer studies carried out at a national level. Furthermore, no previous research has investigated if travel time to hospital services can explain the area-level variation in the incidence of hospital treated self-harm.

Methods From 2009 to 2011, the Irish National Registry of Deliberate Self Harm collected data on selfharm presentations to all hospital emergency departments in the country. The Registry uses standard methods of case ascertainment and also geocodes patient addresses to small area geographical level. Negative binomial regression was used to explore the ecological relationship between area-level self-harm rates and various area-level factors.

Results Deprivation, social fragmentation and population density had a positive linear association with self-harm, with deprivation having the strongest independent effect. Furthermore, self-harm incidence was found to be elevated in areas that had shorter journey times to hospital. However, while this association became attenuated after controlling for other area-level factors it still remained statistically significant. A subgroup analysis examining the effect of travel time on specific methods of self-harm, found that this effect was most marked for self-harm acts involving minor self-cutting.

Conclusions Self-harm incidence was influenced by proximity to hospital services, population density and social fragmentation; however, the strongest area-level predictor of self-harm was deprivation.

\section{INTRODUCTION}

Individual level risk factors for self-harm include, psychiatric illness, youth, female sex, marital status, socioeconomic disadvantage, adverse life events (particularly in childhood), social isolation and sexual orientation. ${ }^{1}$ Knowledge of these individual level risk factors alone has limits for informing strategies aimed at preventing suicidal behaviour, and may potentially mask more distal and conceivably fundamental causes of suicidal behaviour. ${ }^{2}$ To better understand the causes of suicidal behaviour the characteristics of the areas in which people reside need to be examined also. An ecological perspective on self-harm examines how area-level characteristics such as deprivation and social fragmentation influence small area rates of self-harm.
Previous research has shown an inconsistent relationship between the spatial distribution of hospital-treated deliberate self-harm and area-level factors such as deprivation and social fragmentation. A review of the literature conducted by Burrows and Laflamme in $2010,{ }^{3}$ found that a limited number of studies $(\mathrm{N}=13)$ had examined this ecological association between self-harm and area-level risk factors. Overall, the review found that increased area-level socioeconomic disadvantage was associated with increased self-harm incidence, however, this relationship was not found across all studies. Some of the studies in the review found that the relationship between increased levels of deprivation and increased levels of self-harm was stronger in males whereas other studies found the effect of deprivation was stronger in females. ${ }^{4}$ Furthermore, some studies found the effect of deprivation was only seen in younger self-harm populations. ${ }^{5} 6$ Other studies found that deprivation had a stronger effect compared with social fragmentation. ${ }^{4}$

However, many of these studies are confined to urban centres, with few focusing on rural settings and even fewer studies being carried out at a national level. Only one previous study based on self-harm data for the years 2001-2003 was carried out on a national level during the pre-recession Celtic Tiger era in Ireland. ${ }^{7}$

Therefore, large scale up-to-date national studies examining the relationship between area-level factors and self-harm incidence are lacking.

Furthermore, no previous study has examined the effect of proximity to hospital services on the incidence of self-harm as it has been suggested that the high rates of self-harm in urban centres may be explained by the fact that hospital services are typically located in urban centres. To our knowledge, this is the first study to examine how travel time to the nearest hospital emergency department influences area-level incidence rates of self-harm.

This study aims to investigate the area-level relationship between hospital-treated deliberate self-harm, and the following area constructs: deprivation, social fragmentation, population density and, in particular, travel time to the nearest hospital emergency department in the Republic of Ireland (ROI).

\section{METHODS}

\section{Setting}

According to the National Census conducted in 2011 the population of the ROI was 4588252 . 
The population increased by $8.2 \%$ since the previous Census in 2006. Ireland consists of 26 counties and 3409 small areas known as district electoral divisions (DEDs). These 3409 DEDs will be the unit of analysis in this study. There are five cities in the ROI, of which Dublin is the largest with a population of 527612 . The majority of the county of Dublin is urbanised, with almost $28 \%$ of the population residing in this county. The four other cities (Cork, Limerick, Galway and Waterford) are made up of 171 DEDs and together account for 7\% (298 597) of the population.

\section{Self-harm data: the Irish National Registry of Deliberate Self Harm}

Data on deliberate self-harm for the years 2009-2011 were taken from the National Registry of Deliberate Self Harm Ireland. Details of the Registry's case definition and case ascertainment have been previously described in the study by Perry et $a l^{8}$ The Registry is a national system that records and monitors all the self-harm presentations made to each acute hospital across the country.

Data on self-harm presentations are collected by dedicated data registration officers who operate independently of the hospitals and there is standardised application of case definition and inclusion/exclusion criteria. The case definition of self-harm used by the Registry is one that has been developed by the former WHO/Multicentre Study on Parasuicide and has been widely applied in research. ${ }^{9}$ The Registry geocodes the addresses recorded for every self-harm patient to electoral division level.

\section{Deprivation}

An Irish deprivation index known as The Pobal HP Deprivation Index was used in this study. ${ }^{10}$ Most other commonly used deprivation indices are based on a factor analytical approach that reduces a larger number of indicator variables to a smaller number of underlying dimensions or factors. The Pobal HP Deprivation Index does not allow the definition of the underlying dimensions of deprivation to be determined by data-driven techniques, but instead the authors of this index develop a prior conceptualisation of these dimensions. The Pobal HP Deprivation Index consists of three dimensions of affluence/disadvantage: Demographic Profile, Social Class Composition and Labour Market Situation. DEDs were divided into quintiles based on their deprivation score, with quintile 1 containing $20 \%$ of the least-deprived areas and quintile 5 containing $20 \%$ of the most-deprived areas.

\section{Social fragmentation}

The measure of social fragmentation used in this study was based on Congdon's ${ }^{11}$ anomie score. The following four indicators were taken from the 2011 Irish Census: the percentage of unmarried adults; the percentage of single person households; the percentage of persons in private-rented accommodation; and the percentage of persons at a different address 1 year before the 2011 Census. Congdon's measure of social fragmentation was calculated for all small areas by summing the z-scores of each indicator. DEDs were divided into quintiles based on their fragmentation score, with quintile 1 containing 20\% of the least socially fragmented areas and quintile 5 containing $20 \%$ of the most fragmented areas.

\section{Population density-area type}

In this study, urban and rural small areas were distinguished by population density. DEDs were divided into quintiles based on their population density, with quintile 1 (rural areas) containing 20\% of
DEDs with the lowest population density and quintile 5 containing $20 \%$ of the most densely populated DEDs (urban areas).

\section{Travel time to nearest hospital}

In Ireland, the All-Island Research Observatory (AIRO) ${ }^{12}$ calculated the journey times to all hospital emergency departments for every residential address point based on average drive-time speeds (average speed on NAVTEC road network plus 10\% urban area congestion weighting). For the purpose of this study the journey times have been averaged at the DED level. DEDs were divided into quintiles based on their distance in minutes from hospital, with quintile 1 containing 20\% of DEDs that had the shortest journey times and quintile 5 containing $20 \%$ of the DEDs that had the longest journey times.

\section{Statistical analyses}

Self-harm patients with non-household residential addresses such as hospital inpatients, prisoners and the homeless were excluded from this study. During the study time period, the Registry recorded that 1312 (6\%) self-harm patients had a nonhousehold residential address. A considerable proportion of hospital-treated self-harm presentations are due to repeat acts, therefore the number of individuals rather than the number of presentations was used in this study. As there were a limited number of self-harm cases in children and older adults the study population was restricted to the 15-64-year-old age group.

Initially, Poisson regression was carried out and it was found the conditional variance was greater than the conditional mean, which indicated that there may be the presence of over dispersion. Because of this, the negative binomial regression model was considered to be a better fit. All Poisson and negative binomial regression analyses were carried out using Stata V.12. ${ }^{13}$

Negative binomial regression was used to investigate the arealevel relationship between self-harm and the various area-level risk factors. In each of the models adjustment for spatial autocorrelation was made by indicating that the DEDs were clustered by county.

The associations with each of the area-level explanatory variables before and after controlling for the effect of all the other variables were investigated. In the multivariate regression model, the individual components parts that make up the aggregate deprivation as well as the social fragmentation measures were excluded when examining the effects of the aggregate measures themselves.

Wald tests were used to determine the effect modification by age and gender for each of the four area-level explanatory variables. Negative binomial models were also carried out separately for males and females aged 15-39 years and 40-64 years. In each analysis, the lowest quintile (quintile 1) was taken as the reference group. Estimated effects were given as incidence rate ratios with 95\% CIs. In addition to this, negative binomial regression analysis was carried out to examine the effect of how proximity to the nearest hospital department impacted on the method of self-harm seen in hospital emergency departments. Because the covariates population density and distance from hospital are highly correlated with one another, population density was omitted from multivariate analysis. As overdose and self-cutting are the most common types of hospital-treated selfharm seen in Ireland, ${ }^{8}$ the impact of travel time on the incidence of these two self-harm methods was examined. Furthermore, the severity of the self-harm method was examined by distinguishing between major and minor self-cutting and overdoses that involved less than 20 tablets and overdoses that involved more than 20 tablets. 


\section{RESULTS}

Table 1 provides a summary of the number of hospital-treated self-harm patients, the population aged between 15 and 64 years and the four area-level variables, in addition to the individual census indicator components that make up the social fragmentation index and deprivation index.

From 2009 to 2011, a total of 26379 persons aged 1564 years presented with self-harm. Over the 3-year study time period, the number of hospital-treated self-harm patients ranged from 0 to 220 across the DEDs. In all, 981 (29\%) of DEDs reported zero persons with hospital treated self-harm. The population aged 15-64 years in each DED varied greatly across the country with some DEDs having a population as small as 44 and other areas having a population in excess of 24674 . The population density ranged from 0.6 to $1862 / \mathrm{km}^{2}$, the deprivation score ranged from -35.51 to 18.7 and the social fragmentation score ranged from -6.3 to 21.3 . The journey times to the nearest hospital ranged from 5.4 to $232.1 \mathrm{~min}$.

\section{Incidence rates}

From 2009 to 2011, an estimated 26379 persons aged 15-64 years presented with self-harm (table 2). The pooled 2009-2011 all person, male and female incidence rates were 286, 273 and 300 per 100 000, respectively. Across both genders, the self-harm rates were highest in the year 2010 and lowest in 2009. Overall, the rate of self-harm in females was $10 \%$ higher than in males.

Table 1 Summary statistics for all 3409 district electoral divisions (DEDs) in the Republic of Ireland from 2009 to 2011

\begin{tabular}{|c|c|c|c|c|}
\hline & Mean & SD & Minimum & Maximum \\
\hline Population aged $15-64$ years per DED & 901.5 & 1509.5 & 44.0 & 24674 \\
\hline Population density per DED $\left(\mathrm{km}^{2}\right)$ & 692.5 & 1826.1 & 0.6 & 18792 \\
\hline $\begin{array}{l}\text { Social Fragmentation Composite Score } \\
\text { per DED }\end{array}$ & 7.2 & 3.3 & -6.3 & 21.3 \\
\hline \multicolumn{5}{|l|}{ Individual Social Fragmentation Indicators } \\
\hline Unmarried persons (\%) & 60 & 5.6 & 41.3 & 87.9 \\
\hline One person households (\%) & 23.6 & 7.2 & 2.3 & 73.2 \\
\hline Population mobility (\%) & 5.3 & 3.9 & 0.0 & 37.1 \\
\hline Households privately rented (\%) & 10.5 & 11.1 & 0.0 & 89.4 \\
\hline $\begin{array}{l}\text { Pobal HP Deprivation Index Composite } \\
\text { Score per DED }\end{array}$ & -8.5 & 6.3 & -35.5 & 18.7 \\
\hline \multicolumn{5}{|l|}{ Individual deprivation indicators } \\
\hline 5-year population change (\%) & 7.8 & 13.0 & -43.7 & 185.7 \\
\hline Age dependency ratio & 34.9 & 4.6 & 8.2 & 50.8 \\
\hline Lone parents ratio & 16.3 & 11.0 & 0.0 & 75.0 \\
\hline Primary education only (\%) & 18.8 & 7.4 & 1.1 & 53.6 \\
\hline Third-level education (\%) & 25.9 & 10.2 & 1.4 & 84.0 \\
\hline Higher and lower professionals (\%) & 33.7 & 9.8 & 4.1 & 71.9 \\
\hline $\begin{array}{l}\text { Semiskilled and unskilled manual } \\
\text { workers (\%) }\end{array}$ & 18.2 & 6.4 & 2.4 & 51.0 \\
\hline Unemployment rate-male & 21.7 & 8.3 & 0.0 & 65.8 \\
\hline Unemployment rate-female & 13.8 & 6.3 & 0.0 & 50.6 \\
\hline Average persons per room & 0.5 & 0.1 & 0.3 & 1.3 \\
\hline $\begin{array}{l}\text { Travel time in minutes to nearest } \\
\text { hospital per DED }\end{array}$ & 26.5 & 13.7 & 5.4 & 232.1 \\
\hline $\begin{array}{l}\text { Self-harm patients aged } 15-64 \text { years in } \\
2009 \text { per DED }\end{array}$ & 5.0 & 6.8 & 0 & 66 \\
\hline $\begin{array}{l}\text { Self-harm patients aged } 15-64 \text { years in } \\
2010 \text { per DED }\end{array}$ & 5.1 & 7.1 & 0 & 77 \\
\hline $\begin{array}{l}\text { Self-harm patients aged 15-64 years in } \\
2011 \text { per DED }\end{array}$ & 5.2 & 7.3 & 0 & 77 \\
\hline $\begin{array}{l}\text { Self-harm patients aged } 15-64 \text { years in } \\
2009-2011 \text { per DED }\end{array}$ & 10.9 & 18.4 & 0 & 220 \\
\hline
\end{tabular}

Area-level self-harm rates and their ecological relationship with area-level factors

Table 3 shows the unadjusted and adjusted rate ratios for self-harm in all persons aged 15-64 years. In the unadjusted as well as adjusted analyses, a positive linear association was found between increasing self-harm incidence and increasing levels of deprivation, social fragmentation and population density. The findings from the analysis of the subcomponents of deprivation and fragmentation composite measures showed a largely linear association with the exception of age dependency and 5-year population change. However, results from the multivariate analysis found that only three of the subcomponents of deprivation index, namely 5-year population change, the proportion of lone parent households and male and female unemployment rate remained statistically significant. A significant association was found between self-harm incidence and travel to hospital, with self-harm being most elevated in areas nearest to hospital services. Even though this association remained statistically significant after adjustment for the other explanatory variables, the strength of the association was reduced. Overall, deprivation had the strongest independent effect on small area self-harm incidence.

\section{The effect of proximity to nearest hospital on method of self-harm}

In table 4, the findings from the negative binomial model on the effect of travel time to the nearest hospital department (after controlling for deprivation and fragmentation) on the method of self-harm seen at the emergency department are shown. The greatest impact was seen in self-harm acts involving self-cutting, in particular, minor self-cutting, with rates being highest in areas located very close to hospital services.

\section{Stratification by age and gender}

Effect modification by age and gender was examined for each of the four area-level factors and it was found that the strength of the association between self-harm and the various area-level factors differed between the younger and older age groups and between males and females. In table 5 the effects of the arealevel factors on DED rates of self-harm stratified by age and gender is shown. Increasing deprivation had a greater effect on self-harm incidence in the younger age group $\left(\chi^{2}=19.92\right.$, $\mathrm{p}<0.01)$, whereas increased social fragmentation had a greater effect of self-harm incidence in the older group $\left(\chi^{2}=18.64\right.$, $\mathrm{p}<0.01)$. Moreover, a significant interaction between gender and population density was also found $\left(\chi^{2}=18.26, \mathrm{p}<0.01\right)$, with greater levels of population density having a stronger effect on self-harm in males compared with females.

\section{DISCUSSION \\ Main findings}

The results of our study show that deprivation is the strongest independent area-level predictor of self-harm and this finding is

Table 2 The 2009-2011 annual incidences of self-harm in the Republic of Ireland

\begin{tabular}{|c|c|c|c|c|c|c|}
\hline & \multicolumn{2}{|l|}{ Males } & \multicolumn{2}{|c|}{ Females } & \multicolumn{2}{|l|}{ Persons } \\
\hline & $\mathrm{N}$ & Rate & $\mathrm{N}$ & Rate & $\mathrm{N}$ & Rate \\
\hline 2009 & 4056 & 265 & 4470 & 289 & 8526 & 277 \\
\hline 2010 & 4235 & 277 & 4763 & 308 & 8998 & 293 \\
\hline 2011 & 4203 & 275 & 4652 & 301 & 8855 & 288 \\
\hline 2009-2011 & 12494 & 273 & 13885 & 300 & 26379 & 286 \\
\hline
\end{tabular}


Table 3 Effects of deprivation, social fragmentation, population density and travel time to the nearest hospital emergency department on electoral division rates in persons aged 15-64 years

Unadjusted IRR* $95 \% \mathrm{Cl}$

Adjusted IRRT $95 \% \mathrm{Cl}$

\begin{tabular}{|c|c|c|c|c|c|c|c|c|}
\hline & & \\
\hline & Quintile 2 & Quintile 3 & Quintile 4 & Quintile 5 & Quintile 2 & Quintile 3 & Quintile 4 & Quintile 5 \\
\hline Deprivation score & $1.0(0.97$ to 1.13$)$ & $1.2(1.03$ to 1.29$)$ & 1.3 (1.09 to 1.56$)$ & 2.1 (1.75 to 2.57$)$ & $1.4(1.29$ to 1.57$)$ & $1.6(1.46$ to 1.8$)$ & 1.8 (1.59 to 2.02$)$ & 2.5 (2.17 to 2.83$)$ \\
\hline 5-year population change (Q5 highest population decline) & $1.0(0.92$ to 1.12$)$ & $1.1(0.96$ to 1.15$)$ & $1.2(1.07$ to 1.25$)$ & 1.7 (1.49 to 2.04$)$ & 1.1 (1.03 to 1.18$)$ & 1.1 (1.06 to 1.24$)$ & 1.1 (1.07 to 1.22$)$ & $1.3(1.16$ to 1.36$)$ \\
\hline Age dependency & $0.8(0.73$ to 0.91$)$ & 0.8 (0.69 to 0.86$)$ & 0.7 (0.66 to 0.83$)$ & 0.7 (0.59 to 0.76$)$ & $1.0(0.95$ to 1.08$)$ & 10.0 (0.95 to 1.08$)$ & $1.1(1.05$ to 1.17$)$ & $1.1(0.99$ to 1.14$)$ \\
\hline Lone parents & $1.2(1.05$ to 1.4$)$ & $1.4(1.22$ to 1.55$)$ & 2.0 (1.69 to 2.34$)$ & 3.7 (3.13 to 4.45$)$ & $1.1(0.92$ to 1.24$)$ & $1.1(0.99$ to 1.24$)$ & $1.2(1.06$ to 1.45$)$ & $1.4(1.15$ to 1.62$)$ \\
\hline Primary education only & 1.1 (1.02 to 1.26$)$ & 1.2 (1.04 to 1.29$)$ & $1.3(1.11$ to 1.49$)$ & $1.8(1.38$ to 2.35$)$ & 1.1 (1.02 to 1.15$)$ & 1.0 (0.93 to 1.13$)$ & $1.0(0.91$ to 1.1$)$ & $1.1(0.9$ to 1.24$)$ \\
\hline Third-level education (Q5 lowest \% in third-level education only) & $1.0(0.91$ to 1.17$)$ & 1.0 (0.89 to 1.23$)$ & $1.1(0.93$ to 1.29$)$ & 1.7 (1.39 to 2.03$)$ & 1.1 (0.98 to 1.16$)$ & 1.0 (0.88 to 1.12 ) & 1.0 (0.86 to 1.19$)$ & 1.1 (0.92 to 1.28$)$ \\
\hline $\begin{array}{l}\text { Professionals } \\
\text { (Q5 lowest \% of professionals) }\end{array}$ & $1.1(0.97$ to 1.16$)$ & $1.3(1.21$ to 1.38$)$ & $1.5(1.37$ to 1.64$)$ & $2.6(2.21$ to 3.01$)$ & $1.0(0.88$ to 1.11$)$ & $1.0(0.87$ to 1.15$)$ & $0.9(0.77$ to 1.07$)$ & $1.0(0.84$ to 1.18$)$ \\
\hline Manual workers & $1.2(1.05$ to 1.26$)$ & $1.2(1.14$ to 1.33$)$ & $1.6(1.49$ to 1.81$)$ & $2.6(2.19$ to 3.11$)$ & $1.1(1.0$ to 1.23$)$ & 1.1 (0.94 to 1.28$)$ & 1.2 (0.99 to 1.42 ) & 1.3 (1.08 to 1.63$)$ \\
\hline Unemployment rate-male & $1.2(1.09$ to 1.36$)$ & 1.5 (1.29 to 1.67$)$ & $1.9(1.55$ to 2.23$)$ & 2.9 (2.4 to 3.6$)$ & $1.1(1.04$ to 1.21$)$ & 1.2 (1.09 to 1.38$)$ & 1.3 (1.11 to 1.48$)$ & $1.3(1.1$ to 1.51$)$ \\
\hline Unemployment rate-female & $1.2(1.09$ to 1.34$)$ & 1.5 (1.34 to 1.68$)$ & $1.8(1.57$ to 2.1$)$ & 3.1 (2.59 to 3.61$)$ & 1.1 (1.01 to 1.22$)$ & 1.1 (0.98 to 1.24$)$ & 1.2 (1.01 to 1.35$)$ & $1.4(1.15$ to 1.69$)$ \\
\hline Persons per room & $1.0(0.91$ to 1.17$)$ & 1.0 (0.91 to 1.18$)$ & 1.31 .16 to 1.45 & $1.9(1.6$ to 2.25$)$ & $1.0(0.90$ to 1.09$)$ & $1.0(0.86$ to 1.05$)$ & 1.0 (0.85 to 1.09$)$ & 1.0 (0.83 to 1.14$)$ \\
\hline Fragmentation Score & 1.2 (1.1 to 1.4$)$ & $1.4(1.28$ to 1.6$)$ & 2.0 (1.69 to 2.27$)$ & 3.0 (2.49 to 3.72$)$ & 1.1 (1 to 1.27$)$ & 1.2 (1.07 to 1.34$)$ & 1.4 (1.22 to 1.52$)$ & 1.7 (1.47 to 1.87$)$ \\
\hline Unmarried persons & $1.1(0.98$ to 1.17$)$ & $1.3(1.12$ to 1.4$)$ & $1.6(1.45$ to 1.84$)$ & 3 (2.57 to 3.58$)$ & 0.9 (0.88 to 1.02$)$ & $1.0(0.87$ to 1.1$)$ & $1.0(0.90$ to 1.16$)$ & $1.1(0.99$ to 1.3$)$ \\
\hline One person households & $1.0(0.86$ to 1.16$)$ & 1.1 (0.98 to 1.34$)$ & $1.4(1.15$ to 1.67$)$ & 1.9 (1.58 to 2.39$)$ & $1.0(0.92$ to 1.0$)$ & $1.0(0.90$ to 1.08$)$ & 1.1 (0.92 to 1.27$)$ & 1.2 (1.01 to 1.39$)$ \\
\hline Population mobility & $1.3(1.12$ to 1.51$)$ & 1.3 (1.09 to 1.62$)$ & 1.5 (1.26 to 1.85$)$ & $2.0(1.59$ to 2.41$)$ & $1.0(0.90$ to 1.18$)$ & $1.0(0.86$ to 1.17$)$ & $1.0(0.85$ to 1.14$)$ & 0.9 (0.77 to 1.09$)$ \\
\hline Privately rented households & $1.2(0.92$ to 1.46$)$ & $1.6(1.2$ to 2.14$)$ & 1.9 (1.49 to 2.46$)$ & 2.5 (2.03 to 3.05$)$ & 0.9 (0.78 to 1.13$)$ & $1.0(0.86$ to 1.23$)$ & 1.1 (0.9 to 1.34$)$ & 1.1 (0.91 to 1.38$)$ \\
\hline Population density & $1.2(0.97$ to 1.46$)$ & $1.3(1.08$ to 1.63$)$ & $1.8(1.42$ to 2.4$)$ & $3.2(2.44$ to 4.3$)$ & $1.2(1.0$ to 1.52$)$ & 1.4 (1.16 to 1.68$)$ & 1.7 (1.42 to 2.14$)$ & 2.3 (1.84 to 2.79$)$ \\
\hline Travel time to hospital & $0.5(0.44$ to 0.65$)$ & $0.6(0.46$ to 0.68$)$ & 0.6 (0.46 to 0.7$)$ & 0.5 (0.44 to 0.65$)$ & 0.9 (0.78 to 0.94$)$ & 0.8 (0.73 to 0.93$)$ & $0.8(0.71$ to 0.92$)$ & 0.8 (0.69 to 0.89$)$ \\
\hline
\end{tabular}

* Unadjusted effects of each area-level variables before controlling for the effect of the other explanatory variables.

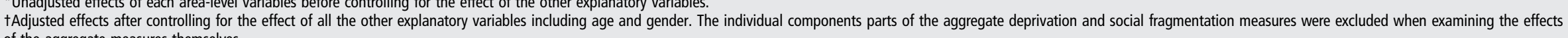
of the aggregate measures themselves.

IRR, internal rate of return.

Table 4 Effects of travel time to nearest hospital on specific methods of self-harm

\begin{tabular}{|c|c|c|c|c|c|c|c|c|}
\hline & \multicolumn{4}{|c|}{ Unadjusted IRR* 95\% Cl } & \multicolumn{4}{|c|}{ Adjusted IRRt 95\% Cl } \\
\hline & Quintile 2 & Quintile 3 & Quintile 4 & Quintile 5 & Quintile 2 & Quintile 3 & Quintile 4 & Quintile 5 \\
\hline All methods of self-harm & 0.5 (0.4 to 0.62$)$ & 0.5 (0.42 to 0.64$)$ & 0.5 (0.41 to 0.65$)$ & $0.5(0.39$ to 0.61$)$ & $0.8(0.68$ to 0.83$)$ & $0.7(0.59$ to 0.74$)$ & 0.6 (0.55 to 0.72$)$ & 0.6 (0.51 to 0.64$)$ \\
\hline Overdose ( $<20$ tablets) & 0.6 (0.49 to 0.78$)$ & $0.6(0.42$ to 0.75$)$ & $0.6(0.46$ to 0.77$)$ & 0.7 (0.5 to 0.87$)$ & $0.9(0.79$ to 1$)$ & $0.8(0.7$ to 0.93$)$ & $0.7(0.63$ to 0.85$)$ & 0.7 (0.57 to 0.78$)$ \\
\hline Overdose (>20 tablets) & $0.6(0.52$ to 0.76$)$ & $0.6(0.54$ to 0.77$)$ & 0.7 (0.54 to 0.79$)$ & $0.6(0.53$ to 0.79$)$ & $0.8(0.75$ to 0.95$)$ & $0.7(0.64$ to 0.82$)$ & $0.7(0.62$ to 0.82$)$ & 0.7 (0.57 to 0.76$)$ \\
\hline Minor self-cutting & 0.5 (0.36 to 0.7$)$ & $0.4(0.29$ to 0.63$)$ & 0.5 (0.35 to 0.72$)$ & $0.4(0.31$ to 0.62$)$ & 0.7 (0.59 to 0.93$)$ & 0.5 (0.35 to 0.7$)$ & $0.5(0.39$ to 0.73$)$ & $0.5(0.35$ to 0.63$)$ \\
\hline Major self-cutting & 0.5 (0.39 to 0.65$)$ & 0.5 (0.37 to 0.71$)$ & $0.5(0.36$ to 0.61$)$ & $0.5(0.39$ to 0.71$)$ & $0.8(0.6$ to 0.97$)$ & $0.6(0.44$ to 0.78$)$ & 0.5 (0.38 to 0.62$)$ & 0.5 (0.42 to 0.71$)$ \\
\hline
\end{tabular}

*Unadjusted effects of each area-level variables before controlling for the effect of the other explanatory variables.

tAdjusted effects after controlling for the effect of deprivation, social fragmentation, age and gender-population density was omitted as population and distance to hospital were highly correlated with one another.

IRR, internal rate of return. 
Table 5 Stratified by age and gender: the effects of deprivation, fragmentation, population density and travel time to nearest hospital on district electoral division self-harm rates

\begin{tabular}{|c|c|c|c|c|}
\hline Explanatory variable & $\begin{array}{l}\text { Males } \\
\text { 15-39-year-olds } \\
\text { IRRt }(95 \% \mathrm{Cl})\end{array}$ & $\begin{array}{l}\text { Males } \\
40-64 \text {-year-olds } \\
\text { IRRt }(95 \% \mathrm{Cl})\end{array}$ & $\begin{array}{l}\text { Females } \\
15-39 \text {-year-olds } \\
\text { IRRt }(95 \% \mathrm{Cl})\end{array}$ & $\begin{array}{l}\text { Females } \\
40-64 \text {-year-olds } \\
\text { IRRt }(95 \% \text { Cl) }\end{array}$ \\
\hline \multicolumn{5}{|c|}{ Deprivation (reference category 1st quintile-least deprived) } \\
\hline 2nd quintile & $1.5^{* * *}(1.31$ to 1.77$)$ & $1.4^{* * *}(1.17$ to 1.61$)$ & $1.5^{* * *}(1.29$ to 1.68$)$ & $1.2^{* *}(1.08$ to 1.44$)$ \\
\hline 3rd quintile & $1.7^{* * *}(1.48$ to 2.01$)$ & $1.6^{* * *}(1.37$ to 1.95$)$ & $1.6^{* * *}(1.41$ to 1.89$)$ & $1.5^{* * *}(1.3$ to 1.67$)$ \\
\hline 4th quintile & $1.9^{* * *}(1.63$ to 2.21$)$ & $1.9^{* * *}(1.5$ to 2.32$)$ & $1.7^{* * *}(1.47$ to 1.96$)$ & $1.7^{* * *}(1.46$ to 1.99$)$ \\
\hline 5th quintile & $2.9^{* * *}(2.31$ to 3.58$)$ & $2.3^{* * *}(1.97$ to 2.8$)$ & $2.5^{* * *}(2.1$ to 2.89$)$ & $2.1^{* * *}(1.82$ to 2.48$)$ \\
\hline \multicolumn{5}{|c|}{ Social fragmentation (reference category 1st quintile-least fragmented) } \\
\hline 2nd quintile & $1.1(0.94$ to 1.34$)$ & $1.3^{*}(1.05$ to 1.49$)$ & $1.1(0.93$ to 1.25$)$ & $1.1(0.91$ to 1.4$)$ \\
\hline 3rd quintile & $1.2(0.97$ to 1.39$)$ & $1.3^{* * *}(1.14$ to 1.52$)$ & $1.1(0.93$ to 1.37$)$ & $1.3^{*}(1.03$ to 1.52$)$ \\
\hline 4th quintile & $1.4^{* * *}(1.18$ to 1.55$)$ & $1.6^{* * *}(1.4$ to 1.89$)$ & $1.2^{*}(1.03$ to 1.43$)$ & $1.4^{* *}(1.17$ to 1.79$)$ \\
\hline 5th quintile & $1.5^{* * *}(1.3$ to 1.82$)$ & $2.3^{* * *}$ (1.91 to 2.72$)$ & $1.4^{* *}(1.14$ to 1.67$)$ & $1.9^{* * *}(1.53$ to 2.27$)$ \\
\hline \multicolumn{5}{|c|}{ Population density (reference category 1st quintile-most rural) } \\
\hline 2nd quintile & $1.2(0.79$ to 1.77$)$ & $1.4^{*}(1.02$ to 1.96$)$ & $1.3^{*}(1.02$ to 1.55$)$ & $1.1(0.79$ to 1.57$)$ \\
\hline 3rd quintile & $1.4^{* *}(1.11$ to 1.86$)$ & $1.6^{* *}(1.14$ to 2.17$)$ & $1.3(1$ to 1.67$)$ & $1.4^{*}(1.03$ to 1.81$)$ \\
\hline 4th quintile & $1.8^{* * *}$ (1.34 to 2.42$)$ & $2^{* * *}(1.59$ to 2.59$)$ & $1.6^{* * *}(1.25$ to 2.09$)$ & $1.7^{* *}(1.19$ to 2.37$)$ \\
\hline 5th quintile & $2.2^{* * *}(1.56$ to 3.14$)$ & $2.7^{* * *}(2.09$ to 3.4$)$ & $2.1^{* * *}(1.62$ to 2.74$)$ & $2.3^{* * *}(1.67$ to 3.15$)$ \\
\hline \multicolumn{5}{|c|}{ Travel time in minutes to nearest hospital (reference category 1st quintile—nearest hospital) } \\
\hline 2nd quintile & $0.8(0.72$ to 1$)$ & $0.8^{* *}(0.67$ to 0.93$)$ & $0.9(0.78$ to 1.04$)$ & $0.9^{* *}(0.77$ to 0.96$)$ \\
\hline 3rd quintile & $0.8^{*}(0.66$ to 0.99$)$ & $0.8^{* *}(0.63$ to 0.91$)$ & $0.9(0.75$ to 1.07$)$ & $0.8^{* *}(0.72$ to 0.94$)$ \\
\hline 4th quintile & $0.7^{* *}(0.6$ to 0.92$)$ & $0.8^{*}(0.66$ to 0.95$)$ & $0.9(0.72$ to 1.03$)$ & $0.9(0.74$ to 1.03$)$ \\
\hline 5th quintile & $0.7^{* *}(0.58$ to 0.88$)$ & $0.7^{* *}(0.53$ to 0.88$)$ & $0.9(0.77$ to 1.08$)$ & $0.8^{* *}(0.71$ to 0.92$)$ \\
\hline
\end{tabular}

${ }^{*} p<0.05,{ }^{* *} p<0.01,{ }^{* * *} p<0.001$.

tAdjusted effects after controlling for the effect of all the other explanatory variables.

IRR, internal rate of return.

consistent with earlier studies. ${ }^{4} 714$ Deprivation was also found to have the greatest effect in the younger age group than the older age group, this is also in line with previous research. ${ }^{6}$ Moreover, the linear association between increasing incidence of self-harm and increasing levels of population density are also consistent with previous studies carried in other countries such as the UK, ${ }^{15}$ the USA ${ }^{16}$ and Finland. ${ }^{17}$ We found that the effect of fragmentation was modified by age with stronger effects being found in the older age groups; this finding is in line with previous research. ${ }^{7}$ However, the relationship between self-harm and fragmentation was weakened after adjustment for the other area-level explanatory variables, and again this finding is in agreement with previous studies. ${ }^{4} 7$

This is the first study to investigate how travel time to the nearest hospital department helps to explain the area-level variation of self-harm. It has been suggested that because hospitals are mainly situated in urban areas, the high rates of self-harm in city/urban areas may be in part explained by proximity to hospital services. ${ }^{7}$ The study findings have shown a significant independent association between self-harm incidence and travel time to hospital. In particular, when examining the effect of proximity to hospital on the various methods of self-harm a striking association was found for minor self-cutting hospital presentations, with minor-self cutting presentations being highest in areas that are located nearest to hospital services. In Ireland, hospital services tend to be located in urban areas, resulting in persons from rural areas having to travel greater distances to reach the nearest hospital. Our findings may suggest that in Ireland, the overall incidence of self-harm and, in particular, hospital-treated self-cutting, may be underestimated and that the lower incidence of self-cutting in rural areas may only be artificially low due to greater distance from hospital services acting as a potential barrier deterring self-harmers residing in rural locations from attending hospital. Alternatively, the lower incidence of minor self-cutting found in rural areas may support the conclusions from other research that self-harmers from rural areas have higher levels of suicidal intent and that an episode of self-harm is more likely to be an act of attempted suicide and consequently this group is less likely to engage in more lethal or severe methods of self-harm such as minor self-cutting. ${ }^{15}$

\section{Strengths and limitations}

A major strength of the study is that it is based on national Registry data that include 26379 persons over a 3-year period. The Pobal HP Deprivation Index (as used in this study) is unique compared with other European deprivation indices, as it includes a specific measure of rural deprivation. ${ }^{18}$ It has been suggested in the literature that the use of deprivation composite measures may fail to identify rural deprivation at small area geography level. ${ }^{19}$ In the Pobal HP Deprivation Index, one of the three dimensions of deprivation is concerned with demographic decline; the authors of this deprivation index argue that demographic decline is the most representative measure of rural deprivation.

A weakness of the study is that the lack of adequate geographical information systems in Ireland compromises the Registry's ability to accurately geocode patient addresses to DED level. ${ }^{7}$ The boundaries of these DEDs have not changed in many years, and because of Ireland's increasing urbanisation and rapidly changing settlement patterns, these DEDs can range in size from as little as 100 persons to as much as 32000 persons. Furthermore, statistical techniques such as multilevel modelling cannot be carried out as the Registry does not collect individual level data on socioeconomic status. This study only examines hospital-treated self-harm, therefore our results may not be generalisable to self-harm cases in the general population as the risk 
factors and profiles of these individuals may be different. The distance decay effect is a geographical term that can be used to describe the interaction between distance and healthcare service utilisation. The distance decay effect is where levels of health services usage decreases as distance from the actual location of the healthcare facility increases. Previous research has found that distance is an important factor in determining health services utilisation. ${ }^{2021}$ As the distance decay effect is primarily an expression of healthcare utilisation, it cannot be interpreted as an indicator of healthcare need, so caution needs to be taken when interpreting our study findings, which have shown that self-harm rates are most elevated in areas that have the shortest travel time to hospital services.

This is the first study to investigate how travel time to the nearest hospital department influences the geographic variation of hospital-treated self-harm. Our findings highlight that persons living greater distances from hospital may be failing to seek hospital treatment for self-harm as increased journey times to hospital services may be acting as a potential deterrent. This poses a potential challenge for health services as this subgroup of the self-harm population may be going undetected and are consequently not receiving the necessary aftercare treatment. While it may be argued that persons engaging in self-harm from remote and rural areas may be accessing local primary care services instead of attending hospital services, data to confirm this possibility are lacking. Furthermore, given the current structure of primary care in Ireland, this is unlikely.

\section{What is already known on this subject}

- Few countries have accurate data on hospital-treated deliberate self-harm. Ireland is the only country in the world that has a national Registry for the population monitoring of hospital-treated deliberate self-harm.

- There is a paucity of large-scale national studies examining how the geographic variation in hospital-treated self-harm can be explained by area-level risk factors.

- Previous research has shown that self-harm incidence is largely an urban phenomenon, yet to date no study has established to what extent the high incidence of hospital-treated self-harm in urban areas can be explained by the fact that hospitals tend to be located in urban areas.

\section{What this study adds}

- This is the first study of its kind to investigate how small area-level variation in hospital-treated self-harm incidence can be explained by proximity to hospital emergency departments, in addition to other area-level risk factors.

- Positive linear associations between increased levels of self-harm and deprivation, social fragmentation and population density were found, with deprivation having the strongest effect.

- Although self-harm incidence was influenced by proximity to hospital services, deprivation was found to be the most important area-level predictor of self-harm. Therefore, resources aimed at tackling self-harm should prioritise these high-risk deprived areas.
Acknowledgements The authors would like to acknowledge all who contributed to the development of the Irish National Registry of Deliberate Self Harm, in particular the data managers and the data registration officers.

Contributors IJP and PC designed the Registry on which the report is based. IBOF, PC and IJP conceived and designed the study. IBOF wrote the initial and subsequent drafts of the manuscripts and PC and IJP revised the manuscript critically for important intellectual content. IBOF carried out the data analysis. All authors have seen and approved the final version of the report.

Funding The Registry is funded by the Irish Health Service Executive's National Office for Suicide Prevention. IBOF is a PhD student whose work is funded by the Health Research Board in Ireland [grant number PHD/2007/16]. Neither the National Office for Suicide Prevention nor the Health Research Board had any role in the study design; the collection and analysis of data; in writing the report; and in the decision to submit the paper for publication.

\section{Competing interests None.}

Ethics approval Ethical approval for the Registry was granted by the Irish National Research Ethics Committee of the Faculty of Public Health Medicine. The National Suicide Research Foundation is registered with the Data Protection Agency and complies with the Irish Data Protection Act of 1988 and the Irish Data Protection (Amendment) Act of 2003.

Provenance and peer review Not commissioned; externally peer reviewed.

\section{REFERENCES}

1 Skegg K. Self-harm. Lancet 2005;366:1471-83.

2 Maris RW. Social and familial risk factors in suicidal behavior. Psychiatr Clin North Am 1997;20:519-50.

3 Burrows S, Laflamme L. Socioeconomic disparities and attempted suicide: state of knowledge and implications for research and prevention. Int I Inj Contr Saf Promot 2010;17:23-40.

4 Gunnell D, Shepherd M, Evans M. Are recent increases in deliberate self-harm associated with changes in socio-economic conditions? An ecological analysis of patterns of deliberate self-harm in Bristol 1972-3 and 1995-6. Psychol Med 2000;30:1197-203.

5 Taylor R, Page A, Morrell S, et al. Mental health and socio-economic variations in Australian suicide. Soc Sci Med 2005;61:1551-9.

6 Hawton $\mathrm{K}$, Harriss L, Hodder K, et al. The influence of the economic and social environment on deliberate self-harm and suicide: an ecological and person-based study. Psychol Med 2001;31:827-36.

7 Corcoran P, Arensman E, Perry IJ. The area-level association between hospital-treated deliberate self-harm, deprivation and social fragmentation in Ireland. J Epidemiol Community Health 2007;61:1050-5.

8 Perry IJ, Corcoran P, Fitzgerald AP, et al. The incidence and repetition of hospital-treated deliberate self harm: findings from the world's first national registry. PLOS ONE 2012;7:e31663.

9 Platt S, Bille-Brahe U, Kerkhof A, et al. Parasuicide in Europe: the WHO/EURO multicentre study on parasuicide. I. Introduction and preliminary analysis for 1989. Acta Psychiatr Scand 1992;85:97-104.

10 Haase TP, Pratschke J. The 2011 Pobal Haase and Pratschke Deprivation Index for Small Areas. Dublin: Pobal, 2012.

11 Congdon P. Suicide and parasuicide in London: a small area study. Urban Stud 1996;33:137-58.

12 All Island Research Observatory (AIRO). All Island accessibility mapping tool. Kildare: All-Island Research Observatory, National University of Ireland Maynooth, 2012.

13 StataCorp. Stata Statistical Software: release 12. College Station, TX: Stat Corporation, 2011.

14 Reimers AM, de Leon AP, Laflamme L. The area-based social patterning of injuries among 10 to 19 year olds. Changes over time in the Stockholm county. BMC Public Health 2008:8:131.

15 Harriss L, Hawton K. Deliberate self-harm in rural and urban regions: a comparative study of prevalence and patient characteristics. Soc Sci Med 2011;73:274-81.

16 Hempstead K. The geography of self-injury: spatial patterns in attempted and completed suicide. Soc Sci Med 2006;62:3186-96.

17 Ostamo A, Lonnqvist J. Excess mortality of suicide attempters. Soc Psychiatry Psychiatr Epidemiol 2001;36:29-35.

18 Haase T, Foley R. Fesability for a local poverty index. Dublin: Combat Poverty Agency, 2009.

19 Barnett S, Roderick P, Martin D, et al. A multilevel analysis of the effects of rurality and social deprivation on premature limiting long term illness. J Epidemiol Community Health 2001;55:44-51.

20 St-Jacques S, Philibert MD, Langlois A, et al. Geographic access to mammography screening centre and participation of women in the Quebec Breast Cancer Screening Programme. J Epidemiol Community Health 2013;67:861-7.

21 Jones AP, Bentham G, Horwell C. Health service accessibility and deaths from asthma. Int J Epidemiol 1999;28:101-5. 